P.C.FIG.175 - DOI: 10.22288/S0004-28032016000100175

\title{
EXPERIÊNCIA INICIAL E RESULTADOS DE 25 RESSECÇÕES HEPÁTICAS REALIZADAS POR UM GRUPO DE CIRURGIA HEPATOBILIAR NO ESTADO DO PIAUI
}

Welligton Ribeiro Figueiredo / Hospital Getulio Vargas; Mayara Magry Andrade da Silva / Hospital Getulio Vargas; Ana Beatriz Silva Lima / UESPI; Ana Clara Alves Ferreira / UESPI; Mychell Holanda Cosme / Uninovafapi; Amanda Maria Barradas Monteiro de Santana / UESPI.

RESUMO - Contexto - Nas últimas duas décadas, ocorreram importantes avanços na cirurgia hepática decorrentes, dentre outras coisas, do melhor entendimento da anatomia hepática e aprimoramento da técnica operatória. Nesse contexto, foi observada redução importante do risco das ressecções hepáticas, assim como ampliação de suas indicações na prática médica. O presente estudo tem como objetivo analisar os resultados iniciais de 25 ressecções hepáticas realizadas por um grupo de cirurgia hepatobiliopancreática no estado do Piaú. Métodos - Foram analisados os prontuários de 25 pacientes submetidos à hepatectomia no estado do Piauí em 7 hospitais no período de janeiro de 2012 a junho de 2016. As variáveis analisadas pelo estudo foram: indicação cirúrgica, tipo de hepatectomia, tempo operatório, necessidade de transfusão sanguínea peroperatória, permanência hospitalar e mortalidade pós-operatória. Resultados - A amostra foi constituída por 12 pacientes do sexo masculino (48\%) e 13 pacientes do sexo feminino (52 \%) com idade entre 28 a 81 anos, com média de 54,5 anos. As indicações foram: hepatocarcinoma (24\%), metástase colorretal (28\%), adenocarcinoma de vesícula (16\%), pseudotumor inflamatório (4\%), adenoma hepatocelular (4\%), metástase de câncer renal (4\%), Doença de Caroli (4\%) e hemangioma (8\%). Foram realizadas 9 hepatectomias esquerdas (36\%), 12 segmentectomias (48\%) e 4 hepatectomias direitas (16\%). O tempo operatório se estendeu de 90 a 240 minutos, com média de 179,5 minutos. O período de internação hospitalar variou de 1 a 14 dias, com média de 4,3 dias. Três pacientes (12\%) necessitaram de transfusão sanguínea, com média de 3,3 concentrados de hemácias. A mortalidade pós-operatória foi de $8 \%$ ( 2 casos), um em consequência de choque hipovolêmico e um devido à insuficiência hepática. Os demais pacientes tiveram evolução pós-operatória satisfatória. Conclusão - A principal indicação de hepatectomia encontrada nesse estudo foi o hepatocarcinoma, sendo a hepatectomia esquerda a modalidade de ressecção hepática mais realizada devido à maior facilidade técnica. O resultado foi satisfatório, a mortalidade foi restrita aos pacientes com mais de 70 anos ou com cirrose hepática, demonstrando que a ressecção hepática está se tornando cada vez mais segura e com bons resultados até para doenças malignas 